\title{
Sarcopenic Obesity: Time to Meet the Challenge
}

\author{
Rocco Barazzonia, b Stephan Bischoff ${ }^{c} \quad$ Yves Boirie $^{d,}$ e \\ Luca Busetto ${ }^{\mathrm{f}} \mathrm{g}$ Tommy Cederholm ${ }^{\mathrm{h}}$ Dror Dicker ${ }^{\mathrm{i}}$ Hermann Toplak ${ }^{\mathrm{j}}$ \\ Andre Van Gossumk ${ }^{k}$ Volkan Yumuk' Roberto Vettor ${ }^{f, g}$ \\ a Internal Medicine, Department of Medical, Surgical and Health Sciences, University of \\ Trieste, Trieste, Italy; ${ }^{\mathrm{b}}$ Azienda Sanitaria Universitaria Integrata di Trieste (ASUITS), Trieste, \\ Italy; ' ${ }^{\mathrm{C}}$ Department of Nutritional Medicine,University of Hohenheim, Stuttgart, Germany; \\ 'Unité de Nutrition Humaine, Université Clermont Auvergne, INRA, UNH, CRNH Auvergne,

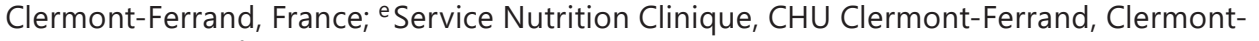 \\ Ferrand, France; ${ }^{f}$ Department of Medicine, University of Padova, Italy; ${ }^{9}$ Center for the Study \\ and the Integrated Management of Obesity (EASO COM), Padova University Hospital, \\ Padova, Italy; hepartment of Public Health and Caring Sciences/Clinical Nutrition and \\ Metabolism, Uppsala University, Uppsala, Sweden; 'Internal Medicine Department \& \\ Obesity Clinic, Hasharon Hospital-Rabin Medical Center, Petach-Tikva, Sackler Faculty of \\ Medicine, Tel Aviv University, Tel Aviv, Israel; jDepartment of Medicine, Medical University \\ Graz, Graz, Austria; ${ }^{k}$ Department of Gastroenterology, Clinic of Intestinal Diseases and \\ Nutritional Support, Hopital Erasme, Free University of Brussels, Brussels, Belgium; \\ 'Division of Endocrinology, Metabolism and Diabetes, Istanbul University Cerrahpasa \\ Medical Faculty, Istanbul, Turkey
}

\section{Keywords}

Obesity · Sarcopenia · Skeletal muscle

\begin{abstract}
The prevalence of overweight and obesity has reached epidemic proportions worldwide due to increasingly pervasive obesogenic lifestyle changes. Obesity poses unprecedented individual, social, and multidisciplinary medical challenges by increasing the risk for metabolic diseases, chronic organ failures, and cancer as well as complication rates in the presence of acute disease conditions. Whereas reducing excess adiposity remains the fundamental pathogenic treatment for obese individuals, complex metabolic and lifestyle abnormalities as well as weight reduction therapies per se may also compromise the ability to preserve muscle function and mass, especially when chronic disease co-exists with obesity. Emerging evidence
\end{abstract}

This statement was developed by the ESPEN and the EASO, and is being published simultaneously in the journals Clinical Nutrition and Obesity Facts

Rocco Barazzoni, MD, PhD

Department of Medical, Surgical and Health Sciences

University of Trieste

Strada di Fiume 447, 34149 Trieste, Italy

barazzon@units.it 
indicates that low muscle mass and quality have a strong negative prognostic impact in obese individuals and may lead to frailty, disability, and increased morbidity and mortality. Awareness of the importance of skeletal muscle maintenance in obesity is however low among clinicians and scientists. The term 'sarcopenic obesity' has been proposed to identify obesity with low skeletal muscle function and mass, but its utilization is largely limited to the aging patient population, and consensus on its definition and diagnostic criteria remains insufficient. Knowledge on prevalence of sarcopenic obesity in various clinical conditions and patient subgroups, on its clinical impacts in patient risk stratification, and on effective prevention and treatment strategies remain therefore dramatically inadequate. In particular, optimal dietary options and medical nutritional support strategies to preserve muscle mass in obese individuals remain largely undefined. The European Society for Clinical Nutrition and Metabolism (ESPEN) and the European Association for the Study of Obesity (EASO) recognize and indicate obesity with altered body composition due to low skeletal muscle function and mass (sarcopenic obesity) as a scientific and clinical priority for researchers and clinicians. ESPEN and EASO therefore call for coordinated action aimed at reaching consensus on its definition, diagnostic criteria, and optimal treatment with particular regard to nutritional therapy. We are convinced that achievement of these goals has a strong potential to reduce the burden of morbidity and mortality in the rapidly increasing obese patient population.

(C) 2018 The Author(s)

Published by S. Karger GmbH, Freiburg

\section{Introduction: What We Know}

\section{Obesity Epidemic}

Obesity is a disease characterized by increased adiposity with negative impact on patient health, and it is commonly diagnosed by body mass index (BMI) above $30 \mathrm{~kg} / \mathrm{m}^{2}$ (or above $27.5 \mathrm{~kg} / \mathrm{m}^{2}$ in specific ethnic groups). Its prevalence has rapidly increased worldwide over the last three decades, largely due to combined genetic predisposition and profound lifestyle changes including sedentary habits and high-calorie dietary intake [1-3]. In many parts of the world, overweight (BMI $>25 \mathrm{~kg} / \mathrm{m}^{2}$ ) and obese individuals currently account for a majority of the population [3-6]; the proportion is substantially higher in middle- and elderly age groups $[7,8]$. This unprecedented shift in body weight paradigms has posed dramatic individual, social, economic and healthcare challenges. Obesity is a strong risk factor for metabolic diseases such as metabolic syndrome and type 2 diabetes as well as atherosclerosis and cardiovascular events $[9,10]$. In addition, obese individuals are at higher risk for many chronic and acute diseases involving end-stage organ failures, cancer, and infections [9-12]. For example, overweight and obese patients carry an at least $70 \%$ higher risk for coronary disease and a $20-50 \%$ higher risk of developing wound infections after colorectal surgery compared to normal-weight patients [13]. Liver steatosis, cirrhosis, and cancer becomes a raising challenge for patients with long-standing obesity [14]. All the above conditions may lead to acute complications and hospitalizations.

\section{Obesity and Skeletal Muscle}

Reducing excess adiposity remains the fundamental pathogenic treatment for obese individuals $[15,16]$. Complex metabolic and lifestyle abnormalities [17-22] as well as weight reduction therapies per se [23] may however also compromise the ability to preserve muscle function and mass. Skeletal muscle changes are not uniformly observed in obese individuals, and heterogeneous phenotypes may contribute to their underestimation. Indeed a positive association between BMI and lean body mass has been reported in general population studies 
[23], and moderate increments in skeletal muscle mass may occur in obesity as a consequence of higher postural and ambulatory muscle work as well as potential direct anabolic effects of higher dietary intake of calorie proteins. It is however increasingly clear that profound skeletal muscle metabolism changes may occur in obesity and may lead to altered body composition with higher fat mass and substantial impairment of muscle mass and quality [24-27]. Various complex interrelated mechanisms may contribute to these changes.

Metabolic and Lifestyle Changes

(1) Primary Metabolic Abnormalities: Clustered metabolic derangements including systemic and muscle oxidative stress, inflammation and insulin resistance may occur in obesity [17-20] due to various causes that primarily include i) excess nutrient availability and tissue delivery, particularly saturated fat [28] and glucose [29] as well as ii) adipose tissue dysfunction upon activation of maladaptive responses in the presence of enhanced demand for lipid storage [30]. These alterations are at least in part causally interrelated and have a strong muscle-catabolic potential [31]; they can also promote a typical 'anabolic resistance' state in skeletal muscle, meaning that the response of muscle protein synthesis to nutrients is blunted [24-27].

(2) Ectopic Muscle Fat Accumulation: Muscle lipid accumulation commonly occurs [30] as a result of insufficient adipose tissue expansion in the face of excess lipid availability [32]; convincing evidence has long demonstrated the close association of skeletal muscle lipid content with tissue and systemic insulin resistance [30,33]. Mechanisms mediating metabolic lipotoxicity are complex and appear to include direct pro-oxidative and inflammatory activities [28] as well as accumulation of metabolically toxic lipid moieties such as diacylglycerol and ceramides [34]. Recent evidences show that ectopic lipid deposition may also compromise muscle protein turnover [35].

(3) Mitochondrial Dysfunction: Mitochondrial changes are not invariably observed in obese skeletal muscle until relatively late stages $[21,22]$. Their onset may however exacerbate oxidative stress and related metabolic cascades leading to insulin resistance and catabolism $[21,22]$. Potential reduction in ATP production may also directly result in low muscle strength and endurance capacity.

(4) Stem Cell Dysfunction: Functionally altered muscle stem cells that may undergo adipocyte differentiation are increasingly described in the context of complicated obesity and muscle fat accumulation [36-38], and their potential relevant role in limiting skeletal muscle mass maintenance has been proposed.

(5) Physical Inactivity: Low physical activity is one fundamental contributor to positive energy balance [22]. Progressive reduction of physical activity is further observed with disease progression due to worsening obesity and its joint and musculoskeletal complications [22], with direct negative impact on muscle protein turnover and muscle oxidative and performance capacity $[39,40]$.

Comorbidities and Treatment

(1) Cardiometabolic Complications: Complications such as metabolic syndrome or overt type 2 diabetes and hyperglycemia are associated with enhanced oxidative stress, pro-inflammatory changes, and mitochondrial dysfunction $[21,29]$ that commonly cause catabolic abnormalities and may independently further muscle alterations. Altered tissue perfusion in the presence or absence of clinically relevant atherosclerotic disease as well as epicardial fat enlargement may also cause metabolic complications by enhancing ROS production and their negative metabolic impact [41,42].

(2) Chronic and Acute Complications: Obesity directly enhances the risk for, or may be associated with chronic organ failure syndromes and chronic diseases (including chronic 
heart failure, chronic kidney disease, chronic obstructive pulmonary disease, obstructive sleep apnea syndrome, and cancer) as well as their acute complications [10-12]. All of the above events and conditions may result in heterogeneous sources of inflammation and oxidative stress [43-48] while impairing spontaneous physical activity, thereby synergistically enhancing muscle loss and dysfunction [49].

(3) Surgical and Medical Treatment: Bariatric procedures are becoming increasingly common and almost invariably lead to skeletal muscle catabolism, at least in the initial rapid weight loss phase, characterized by profoundly negative energy balance [50]; low- or very-low-calorie diets are associated with similar qualitative changes although to less pronounced degrees $[23,51]$.

A multifactorial network of clustered alterations therefore appears to occur in obesity that may account for skeletal muscle derangements. While these changes are not inevitable, they become increasingly likely in patients with longer obesity duration, complications, and comorbidities as well as in elderly individuals that may undergo muscle changes also due to aging per se [52]. Most mechanisms directly reduce muscle anabolism, thereby reducing muscle mass as previously described [24-27]. In addition, several alterations have a negative impact on muscle quality in terms of strength per muscle unit and endurance capacity. The latter include muscle fat accumulation that reduces muscle density and quality with lower contractile protein content per unit tissue $[35,53,54]$, mitochondrial dysfunction that may cause impaired ATP production, and maximal oxygen consumption leading to both reduced strength and endurance [21]. Physical inactivity that reduces muscle mass, mitochondrial biogenesis and function, and tissue lipid oxidation, also leads to reduced strength and endurance potentially enhancing tissue and systemic inflammation and oxidative stress [39, $40,55]$.

\section{Skeletal Muscle Changes and Outcome}

A profound negative clinical impact of low skeletal muscle function and mass is unequivocally emerging in many disease conditions and in aging [52, 56, 57]. A similar negative impact is also emerging in obesity despite potential difficulties in identifying and defining muscle changes within the obese phenotype [58-60]. Available studies indeed described muscle changes through heterogeneous definitions and methodologies including body composition analysis, muscle strength, or cardiorespiratory fitness and physical capacity [61-64]. With this limitation in mind, obese individuals with low muscle mass or functional parameters had higher risk of developing frailty and disability, and therefore poor quality of life $[65,66]$. Risk for frailty and disability in obese individuals with low muscle function and mass has been reported to be significantly higher than that observed in non-obese counterparts with similar muscle alterations [65]. This could appear as contradictory to the so-called 'obesity paradox', but it means that obesity does not protect from chronic disease-related mortality when it is associated with sarcopenia. Indeed low or declining muscle mass is emerging as a negative prognostic factor associated with higher morbidity and mortality in obese patients with chronic diseases $[67,68]$. Obese individuals with gastrointestinal cancers and low muscle mass accordingly had higher risk of dying than matched obese patients without muscle abnormalities [68]. In obese heart failure patients, low physical capacity also predicted poor outcome [62]. In chronic kidney disease patients, direction of changes in muscle mass was the major determinant of survival independently of direction of changes of total body weight [70]. We conclude that i) available evidence, despite limitations and heterogeneity, points towards an important role of skeletal muscle changes with altered function and mass in negatively modulating obese patient morbidity and mortality; and that ii) preventing and/or treating muscle changes has therefore relevant potential to improve obesity-associated morbidity and mortality. 
Table 1. The following areas are identified as suffering from limitations in knowledge and/or consensus and are proposed for focused, coordinated action in obese individuals with low muscle function and mass
Sarcopenic obesity: limitations and needs

Basic knowledge

Diagnostic tools

Diagnostic criteria

Prevention and treatment

Patient subgroup and clinical settings definition

\section{Where We Are - Sarcopenic Obesity: Limitations and Needs}

Low muscle function and mass are currently addressed in obese individuals under the definition of sarcopenic obesity. The latter is based on the originally geriatric concept of sarcopenia, i.e. the age-associated combination of declining muscle mass and function (particularly muscle strength) [52]. A definition of primary, age-associated sarcopenia and corresponding diagnostic criteria have been proposed [52], but relevant methodological issues and clinical thresholds for defining criteria remain under debate. The current definitions of sarcopenic obesity combine sarcopenia, as defined through variable criteria, with the presence of obesity either defined as BMI $>30 \mathrm{~kg} / \mathrm{m}^{2}$ or by adiposity levels [61,71-73]. We believe that these concepts and available results represent important starting points, but do not currently allow for satisfactory patient identification, clinical stratification, and thus treatment. As a direct consequence, awareness of the relevance of skeletal muscle maintenance in obesity remains inadequate among researchers and clinicians. We specifically identify the following limitations and needs (table 1).

Basic Knowledge

- Limitations: Although several mediators and metabolic pathways involved in the onset of skeletal muscle catabolism and anabolic dysfunction have been elucidated, knowledge remains incomplete.

- Needs: Research should continue to elucidate fundamental issues in terms of molecular and endocrine mediators regulating skeletal muscle function and mass as well as amino acid metabolism, with particular regard to cross-talk and interactions between skeletal muscle and adipose tissue also at stem cell level. Additional important areas include mediators of positive effects of exercise, the role of gut hormonal systems and microbiota metabolism and their nutritional regulation in altering skeletal muscle homeostasis with potential muscle-catabolic systemic alterations [74], the role of brain regulation of physical and skeletal muscle activities [75]. Also importantly, research should aim at elucidating potential disease-specific mechanisms that could interact with obesity in regard to negatively affecting muscle function and mass in the presence of various complications and comorbidities.

\section{Patient Groups and Clinical Settings}

- Limitations: The concept of sarcopenia and sarcopenic obesity have been primarily defined and applied in geriatric populations [8, 52,65]. Although the parallel concept of secondary sarcopenia was introduced to refer to all-cause early onset of muscle loss and dysfunction, we are convinced that substantial work is needed to enhance awareness of the strong risk for muscle changes in obese individuals at any age.

- Needs: Awareness of the risk of muscle changes should be particularly promoted at any ageforobeseindividuals in the presence ofmetabolic complications, chroniccomorbidities, 
acute or critical illness, and following bariatric surgery or hypocaloric diet. Disability and frailty may occur in obese geriatric and non-geriatric patients and should be evaluated through medical history and clinical assessment in obese individuals at risk for, or already presenting with, clinical comorbidities. It should also be pointed out that patient characteristics and therapeutic needs for low muscle function and mass may vary substantially in different settings; this fundamental issue should be appropriately recognized and addressed.

\section{Diagnostic Tools}

- Limitations: As mentioned above, identification of diagnostic tools to measure skeletal muscle and fat mass as well as skeletal muscle function has proven generally problematic, particularly in terms of combining precision, safety, and routine applicability in clinical practice. It should be pointed out that simple anthropometric measurements may be biased in obese individuals by confounding adipose depots. Radiological methodologies that include nuclear magnetic resonance spectroscopy, selected CT scans or dual energy X-ray absorptiometry (DEXA) have been considered potentially most accurate but are not readily available and may involve X-ray exposure [64]. Bioelectrical impedance analysis has been considered and proposed as a potential acceptable compromise in terms of invasiveness, accuracy, and applicability in the absence of confounding fluid balance abnormalities [76, 77]. Functional measures also are heterogeneous and include hand-grip, knee extensor strength, and various mobility measurements involving postural or walking tests [64].

- Needs: There is obviously no ideal methodology to simultaneously achieve maximal precision, safety, and routine applicability. Since the latter is ultimately sought, surrogate markers may have to be accepted as reasonable compromises (e.g. as similarly applied for waist circumference relative to abdominal visceral fat). To reach larger consensus on diagnostic tools, homogeneous datasets should be ideally evaluated or created to identify gold standard techniques and corresponding acceptable, readily applicable surrogate markers. Although apparently adding to complexity, such efforts should also aim at evaluating homogeneous patient groups, and potential different optimal approaches in different patient groups should be considered.

\section{Diagnostic Criteria}

- Limitations: Diagnostic criteria for obesity with low muscle function and mass currently suffer from lack of widespread consensus on diagnostic tools and related difficulties in comparing different outcome measures in different studies [61, 71-73]. Normalization of available outcomes into indexes attempting to normalize measured information may be appropriate, but it also may result in enhanced variability. Application of different criteria to identify sarcopenic obesity may therefore currently lead to substantially and, unfortunately, clinically unacceptable variable prevalence levels.

- Needs: Overcoming lack of consensus will likely require further evaluation or creation of databases that should be ideally acquired in the context of homogeneous methodologies and designs. Systematic efforts to integrate measurements of both muscle and fat mass and their relationships, as well as their body distribution, in the concept of sarcopenic obesity are also missing $[77,78]$. We believe that such efforts should also be undertaken, based on evidence of fundamental pathogenetic inter-relationships between adipose and skeletal muscle mass, distribution, and function. 


\section{Prevention and Treatment}

- Limitations: Under the above-described conditions it is perhaps not surprising that prevention and treatment of low muscle function and mass in obese individuals are both difficult and under-implemented. Multimodal therapeutic strategies should include physical activity and nutrition [79-82] that should in turn offers adequate high-quality protein intake $[83,84]$ or protein / amino acid administration in patients in need of medical nutrition [83-85]. As previously discussed, heterogeneity in patients groups, treatment protocols, and outcome measures make it difficult to compare and interpret study results. Use of nutraceuticals to stimulate anabolism beyond anabolic resistance has also been advocated and tested, but variable protocols, treatment duration, and dose prevent final conclusions on their efficacy [86].

- Needs: Identification of optimal prevention and treatment modalities aimed at preserving and increasing skeletal muscle function and mass in obesity is of urgent priority, and potential use of nutraceuticals besides optimal macronutrient composition should be specifically addressed [86]. It should however be pointed out that, despite gaps and limitations in knowledge, a large and growing body of evidence provides strong support for an association of protein and amino acid intake as well as skeletal muscle anabolism with maintenance of lean body mass [83, 84]. It therefore seems that routinely recommending and ensuring adequate protein intake of $1 \mathrm{~g} / \mathrm{kg}$ ideal body weight per day as recommended intake in healthy non-geriatric populations is reasonable and safe, with higher amounts for high-risk patient groups in the absence of contraindications (see paragraph below). We also need to emphasize that exercise training or physical therapy have repeatedly been proven effective in improving muscle function and mass, and appropriate and safe exercise levels relative to the level of comorbidities and disabilities should be routinely recommended in obese patients [80-82].

\section{Current Approach - What We Can Do}

We are aware that existing limitations in current approaches to obese individuals with low muscle function and mass must not limit our efforts to provide the best possible clinical assessment and treatment. We propose the following approaches:

- Awareness: We believe that risk of skeletal muscle loss and dysfunction should be considered in obese patients, particularly in the presence of advanced age ( $>65$ years) or when concomitant metabolic complications, chronic diseases, or acute complications occur. Efforts should be made to monitor skeletal muscle function and mass and to prevent or minimize its loss in patients undergoing bariatric surgery procedures, with particular regard to malabsorptive ones, and in those undergoing hypocaloric dietary treatment particularly in the presence of advanced age and/or comorbidities. It may also concern patients recovering from critical illness or after long immobilization as in ICU [48], as well as patients suffering from specific endocrine disorders (diabetes, hypogonadism, Cushing syndrome, or long-term glucocorticoid treatment).

- Assessment - Skeletal Muscle Function and Mass, Functional Status and Disabilities: When loss of skeletal muscle mass and/or function is suspected or appears likely based on medical history and examination, clinical assessment should include measurement of body composition and muscle strength by available techniques, such as bioelectrical impedance analysis, handgrip test or walking test. Such information may be useful not only for identification of muscle changes but also for longitudinal patient monitoring over time. We support the concept that global assessment of obese individuals should include functional status, particularly in the presence of complications and comorbidities. 
The recently proposed Edmonton obesity staging system [87] provides a potential example of staging tools including disability assessment that may in turn largely reflect loss of skeletal muscle function and mass. Presence of components of frailty could also be assessed to the same purpose not only in elderly individuals but in all at-risk patients.

- Prevention and Treatment - Nutrition and Physical Activity: In patients with clinical evidence for loss of skeletal muscle function and mass or in those with at-risk conditions such as metabolic complications, chronic and acute disease and advanced age as well as in those undergoing weight loss programs, treatment should be associated with precautions to prevent, limit, or treat skeletal muscle alterations. Such approaches should include nutritional care and physical exercise. Based on available evidence [83, 84], adequate protein intake of $1 \mathrm{~g} / \mathrm{kg}$ ideal body weight per day should be provided in healthy non-geriatric individuals. In addition, higher protein intakes are increasingly recommended by guidelines and expert groups for high-risk patients. The latter include aged individuals and hemodialysis patients [83]. Obese ICU patients undergoing acute metabolic stress with likely substantial muscle loss and weakness have been specifically addressed in recent guidelines with recommendations of very high protein intakes of up to $2.2 \mathrm{~g} / \mathrm{kg}$ day through medical nutritional support [84]. Hypocaloric diets with unbalanced macronutrient composition and higher protein levels are considered acceptable by recent guidelines $[15,16]$ and could become more routinely recommended particularly in patients with low muscle function and mass in need to undergo weight loss treatment, or in those at higher risk of developing such changes during weight loss. Oral protein supplements should be considered when sufficient dietary intake is not possible [88]. As previously anticipated, appropriate and safe exercise levels relative to comorbidities and disabilities should be routinely implemented. Physical support rehabilitation should finally be implemented whenever possible according to patient status [89].

\section{Conclusion: A Call for Action}

The European Society for Clinical Nutrition and Metabolism (ESPEN) and the European Association for the Study of Obesity (EASO) recognize and indicate obesity with altered body composition due to low skeletal muscle function and mass (sarcopenic obesity) as a scientific and clinical priority. ESPEN and EASO therefore call for coordinated action aimed at increasing awareness on this topic among researchers and clinicians, and at promoting research and initiatives aimed at reaching evidence-based consensus on diagnostic tools, definition, and diagnostic criteria as well as optimal treatment. ESPEN and EASO aim at directly contributing by promoting the topic in workshops, meeting sessions and educational initiatives, by fostering networking and collaboration among interested scientists and experts, and by promoting awareness and disseminating evidence on best available diagnostic tools and on treatment options with particular regard to diet and medical nutritional support. We are convinced that achievement of these goals has a strong potential to reduce the burden of morbidity and mortality in the dramatically increasing obese patient population across all medical specialties.

\section{Disclosure Statement}

The authors have no conflicts of interest to declare relative to the current work. 
Barazzoni et al.: Sarcopenic Obesity: Time to Meet the Challenge

\section{References}

1 Branca F, Nikogosian H, Lobstein T (eds): The Challenge of Obesity in the WHO European Region and the Strategies for Response: Summary. Copenhagen, WHO Regional Office for Europe, 2007.

2 Withrow D, Alter D: The economic burden of obesity worldwide: a systematic review of the direct costs of obesity. Obes Rev 2010;12:131-141.

-3 NCD Risk Factor Collaboration (NCD-RisC): Trends in adult body-mass index in 200 countries from 1975 to 2014:a pooled analysis of 1698 population-based measurement studies with 19.2 million participants. Lancet 2016;387:1377-1396.

4 Kelly T, Yang W, Chen CS, Reynolds K, He J: Global burden of obesity in 2005 and projections to 2030. Int J Obes (Lond) 2008;32:1431-1437.

5 Berrington de Gonzalez A, Hartge P, Cerhan JR, et al: Body-mass index and mortality among 1. 46 million white adults. N Engl J Med 2010;363:2211-2219.

6 Global BMI Mortality Collaboration, Di Angelantonio E, Bhupathiraju ShN, et al: Body-mass index and all-cause mortality: individual-participant-data meta-analysis of 239 prospective studies in four continents. Lancet 2016;388:776-786.

7 Ruesten A, Steffen A, Floegel A, Van der A DL, Masala G, Tjonneland A, et al: Trend in obesity prevalence in European adult cohort populations during follow-up since 1996 and their predictions to 2015. PLoS One 2011; 6:e27455.

8 Mathus-Vliegen EM1; Obesity Management Task Force of the European Association for the Study of Obesity. Prevalence, pathophysiology, health consequences and treatment options of obesity in the elderly: a guideline. Obes Facts 2012;5:460-483.

-9 Alberti KGMM, Eckel RH, Grundy SM, Zimmet PZ, Cleeman JI, Donato KA, Fruchart JC, James WP, Loria CM, Smith SC Jr; International Diabetes Federation Task Force on Epidemiology and Prevention; National Heart, Lung, and Blood Institute; American Heart Association; World Heart Federation; International Atherosclerosis Society; International Association for the Study of Obesity:Harmonizing the metabolic syndrome: a joint interim statement of the International Diabetes Federation Task Force on Epidemiology and Prevention; National Heart, Lung, and Blood Institute; American Heart Association; World Heart Federation; International Atherosclerosis Society; and International Association for the Study of Obesity. Circulation 2009;120:16401645.

10 Fruhbeck G, Toplak H, Woodward E, et al: Obesity: the gateway to ill health - an EASO position statement on a rising public health, clinical and scientific challenge in Europe. Obes Facts 2013;6:117-20.

11 Bauer UE, Briss PA, Goodman RA, Bowman BA: Prevention of chronic disease in the 21st century: elimination of the leading preventable causes of premature death and disability in the USA. Lancet 2014;384:45-52.

$\$ 12$ Bischoff SC, Boirie Y, Cederholm T, Chourdakis M, Cuerda C, Delzenne NM, Deutz NE, Fouque D, Genton L, Gil C, Koletzko B, Leon-Sanz M, Shamir R, Singer J, Singer P, Stroebele-Benschop N, Thorell A, Weimann A, Barazzoni R: Towards a multidisciplinary approach to understand and manage obesity and related diseases. Clin Nutr. 2017;36:917-938.

13 Gurunathan U, Ramsay S, Mitrić G, Way M, Wockner L, Myles P: Association between obesity and wound infection following colorectal surgery: systematic review and meta-analysis. J Gastrointest Surg 2017;21: 1700-1712.

14 Michelotti GA, Machado MV, Diehl AM: NAFLD, NASH and liver cancer. Nat Rev Gastroenterol Hepatol 2013; 10:656-665.

-15 Jensen MD, Ryan DH, Apovian CM, Ard JD, Comuzzie AG, Donato KA, Hu FB, Hubbard VS, Jakicic JM, Kushner RF, Loria CM, Millen BE, Nonas CA, Pi-Sunyer FX, Stevens J, Stevens VJ, Wadden TA, Wolfe BM, Yanovski SZ: 2013 AHA/ACC/TOS guideline for the management of overweight and obesity in adults: a report of the American College of Cardiology/American Heart Association Task Force on Practice Guidelines and The Obesity Society. J Am Coll Cardiol 2014;63:2985-3023.

-16 Yumuk V, Tsigos C, Fried M, Schindler K, Busetto L, Micic D, Toplak H; Obesity Management Task Force of the European Association for the Study of Obesity: European Guidelines for Obesity Management in Adults. Obes Facts 2015;8:402-424.

17 Furukawa S, Fujita T, Shimabukuro M, Iwaki M, Yamada Y, Nakajima Y, Nakayama O, Makishima M, Matsuda M, Shimomura I: Increased oxidative stress in obesity and its impact on metabolic syndrome. J Clin Invest 2004;114:1752-1761.

18 Schenk S, Saberi M, Olefsky JM: Insulin sensitivity: modulation by nutrients and inflammation. J Clin Invest 2008;118:2992-3002.

19 Samuel VT, Shulman GI: The pathogenesis of insulin resistance: integrating signaling pathways and substrate flux. J Clin Invest 2016;126:12-22.

20 Montgomery MK, Turner N: Mitochondrial dysfunction and insulin resistance: an update. Endocr Connect 2015;4:R1-R15.

21 Dahlmans D, Houzelle A, Schrauwen P, Hoeks J: Mitochondrial dynamics, quality control and miRNA regulation in skeletal muscle: implications for obesity and related metabolic disease. Clin Sci 2016 130:843-852.

22 Strasser B: Physical activity in obesity and metabolic syndrome. Ann N Y Acad Sci 2013;1281:141-159.

23 Cava E, Yeat NC, Mittendorfer B: Preserving healthy muscle during weight loss. Adv Nutr 2017;8:511-519. 
Guillet C, Delcourt I, Rance M, Giraudet C, Walrand S, Bedu M, Duche P, Boirie Y: Changes in basal and insulin and amino acid response of whole body and skeletal muscle proteins in obese men. J Clin Endocrinol Metab 2009;94:3044-3050.

25 Murton AJ, Marimuthu K, Mallinson JE, Selby AL, Smith K, Rennie MJ, Greenhaff PL: Obesity appears to be associated with altered muscle protein synthetic and breakdown responses to increased nutrient delivery in older men, but not reduced muscle mass or contractile function. Diabetes 2015;64:3160-3171.

-26 Beals JW, Sukiennik RA, Nallabelli J, Emmons RS, van Vliet S, Young JR, Ulanov AV, Li Z, Paluska SA, De Lisio M, Burd NA: Anabolic sensitivity of postprandial muscle protein synthesis to the ingestion of a protein-dense food is reduced in overweight and obese young adults. Am J Clin Nutr 2016;104:1014-1022.

-27 Smeuninx B, Mckendry J, Wilson D, Martin U, Breen L: Age-related anabolic resistance of myofibrillar protein synthesis is exacerbated in obese inactive individuals. J Clin Endocrinol Metab 2017;102:3535-3545.

-28 Barazzoni R, Zanetti M, Gortan Cappellari G, Semolic A, Boschelle M, Codarin E, Pirulli A, Cattin L, Guarnieri G: Fatty acids acutely enhance insulin-induced oxidative stress and cause insulin resistance by increasing mitochondrial reactive oxygen species (ROS) generation and nuclear factor- $\kappa \mathrm{B}$ inhibitor (IкB)-nuclear factor- $\kappa \mathrm{B}$ $(\mathrm{NF} \kappa \mathrm{B})$ activation in rat muscle, in the absence of mitochondrial dysfunction. Diabetologia 2012;55:773-782.

-29 Barazzoni R, Deutz NEP, Biolo G, Bischoff S, Boirie Y, Cederholm T, Cuerda C, Delzenne N, Leon Sanz M, Ljungqvist O, Muscaritoli M, Pichard C, Preiser JC, Sbraccia P, Singer P, Tappy L, Thorens B, Van Gossum A, Vettor R, Calder PC: Carbohydrates and insulin resistance in clinical nutrition: recommendations from the ESPEN expert group. Clin Nutr 2017;36:355-363.

30 Czech MP: Insulin action and resistance in obesity and type 2 diabetes. Nat Med 2017;23:804-814.

-31 Powers SK, Morton AB, Ahn B, Smuder AJ: Redox control of skeletal muscle atrophy. Free Radic Biol Med 2016; 98:208-217.

-32 Cuthbertson DJ, Steele T, Wilding JP, Halford JC, Harrold JA, Hamer M, Karpe F: What have human experimental overfeeding studies taught us about adipose tissue expansion and susceptibility to obesity and metabolic complications? Int J Obes 2017;41:853-865.

-33 Mingrone G, Rosa G, Di Rocco P, Manco M, Capristo E, Castagneto M, Vettor R, Gasbarrini G, Greco AV: Skeletal muscle triglycerides lowering is associated with net improvement of insulin sensitivity, TNF-alpha reduction and GLUT4 expression enhancement. Int J Obes Relat Metab Disord 2002;26:1165-1172.

-34 Lipina C, Hundal HS: Lipid modulation of skeletal muscle mass and function. J Cachexia Sarcopenia Muscle 2017;8:190-201.

-35 Tardif N, Salles J, Guillet C, Tordjman J, Reggio S, Landrier JF, Giraudet C, Patrac V, Bertrand-Michel J, Migne C, Collin ML, Chardigny JM, Boirie Y, Walrand S: Muscle ectopic fat deposition contributes to anabolic resistance in obese sarcopenic old rats through eIF2 $\alpha$ activation. Aging Cell 2014;13:1001-1111.

- 36 Vettor R, Milan G, Franzin C, Sanna M, De Coppi P, Rizzuto R, Federspil G: The origin of intermuscular adipose tissue and its pathophysiological implications. Am J Physiol Endocrinol Metab 2009 297:E987-E998.

-37 Scarda A, Franzin C, Milan G, Sanna M, Dal Prà C, Pagano C, Boldrin L, Piccoli M, Trevellin E, Granzotto M, Gamba P, Federspil G, De Coppi P, Vettor R: Increased adipogenic conversion of muscle satellite cells in obese Zucker rats. Int J Obes 2010;34:1319-1327.

38 Thornell LE: Sarcopenic obesity: satellite cells in the aging muscle. Curr Opin Clin Nutr Metab Care 2011;14: 22-27.

-39 Biolo G, Agostini F, Simunic B, Sturma M, Torelli L, Preiser JC, Deby-Dupont G, Magni P, Strollo F, di Prampero P, Guarnieri G, Mekjavic IB, Pisot R, Narici MV: Positive energy balance is associated with accelerated muscle atrophy and increased erythrocyte glutathione turnover during 5 wk of bed rest. Am J Clin Nutr 2008;88: 950-958.

40 Kang C, Ji LL: Muscle immobilization and remobilization downregulates PGC-1 $\alpha$ signaling and the mitochondrial biogenesis pathway. J Appl Physiol 2013;115:1618-1625.

-41 Hoppeler H, Vogt M, Weibel ER, Fluck M: Response of skeletal muscle mitochondria to hypoxia. Exp Physiol 2003;88:109-119.

-42 Trayhurn P: Hypoxia and adipose tissue function and dysfunction in obesity. Physiol Rev 2013;93:1-21.

43 Barazzoni R, Biolo G, Zanetti M, Bernardi A, Guarnieri G: Inflammation and adipose tissue in uremia. J Ren Nutr 2006;16:204-207.

-44 Deger SM, Hung AM, Gamboa JL, Siew ED, Ellis CD, Booker C, Sha F, Li H, Bian A, Stewart TG, Zent R, Mitch WE, Abumrad NN, Ikizler TA: Systemic inflammation is associated with exaggerated skeletal muscle protein catabolism in maintenance hemodialysis patients. JCI Insight 2017;2: pii: 95185.

45 Rahman A, Jafry S, Jeejeebhoy K, Nagpal AD, Pisani B, Agarwala R: Malnutrition and cachexia in heart failure. JPEN J Parenter Enteral Nutr 2016;40:475-486.

-46 Dolan RD, Lim J, McSorley ST, Horgan PG, McMillan DC: The role of the systemic inflammatory response in predicting outcomes in patients with operable cancer: Systematic review and meta-analysis. Sci Rep 2017; 7 16717.

-47 Crossland H, Constantin-Teodosiu D, Gardiner SM, Constantin D, Greenhaff PL: A potential role for Akt/FOXO signalling in both protein loss and the impairment of muscle carbohydrate oxidation during sepsis in rodent skeletal muscle. J Physiol 2008;586:5589-5600. 
Barazzoni et al.: Sarcopenic Obesity: Time to Meet the Challenge

48 Puthucheary ZA, Rawal J, McPhail M, Connolly B, Ratnayake G, Chan P, Hopkinson NS, Phadke R, Dew T, Sidhu PS, Velloso C, Seymour J, Agley CC, Selby A, Limb M, Edwards LM, Smith K, Rowlerson A, Rennie MJ, Moxham J, Harridge SD, Hart N, Montgomery HE: Acute skeletal muscle wasting in critical illness. JAMA 2013;310: 1591-1600.

49 Brocca L, Cannavino J, Coletto L, Biolo G, Sandri M, Bottinelli R, Pellegrino MA: The time course of the adaptations of human muscle proteome to bed rest and the underlying mechanisms. J Physiol 2012;590:5211-5230.

-50 Ciangura C, Bouillot JL, Lloret-Linares C, Poitou C, Veyrie N, Basdevant A, Oppert JM: Dynamics of change in total and regional body composition after gastric bypass in obese patients. Obesity (Silver Spring) 2010;18: $760-765$.

-51 Chaston TB, Dixon JB, O’Brien PE: Changes in fat-free mass during significant weight loss: a systematic review. Int J Obes 2007;31:743-750.

-52 Cruz-Jentoft AJ, Baeyens JP, Bauer JM, Boirie Y, Cederholm T, Landi F, Martin FC, Michel JP, Rolland Y, Schneider SM, Topinkova E, Vandewoude M, Zamboni M; European Working Group on Sarcopenia in Older People: Sarcopenia: European consensus on definition and diagnosis: Report of the European Working Group on Sarcopenia in Older People. Age Ageing 2010;39:412-423.

53 Marcus RL, Addison O, Dibble LE, Foreman KB, Morrell G, Lastayo P: Intramuscular adipose tissue, sarcopenia, and mobility function in older individuals. J Aging Res 2012;2012:629637.

54 Beavers KM, Beavers DP, Houston DK, Harris TB, Hue TF, Koster A, Newman AB, Simonsick EM, Studenski SA, Nicklas BJ, Kritchevsky SB: Associations between body composition and gait-speed decline: results from the Health, Aging, and Body Composition study. Am J Clin Nutr 2013;97:552-560.

-55 Wall BT, Dirks ML, van Loon LJ: Skeletal muscle atrophy during short-term disuse: implications for age-related sarcopenia. Ageing Res Rev 2013:12:898-906.

-56 Landi F, Liperoti R, Russo A, Giovannini S, Tosato M, Capoluongo E, Bernabei R, Onder G: Sarcopenia as a risk factor for falls in elderly individuals: results from the ilSIRENTE study. Clin Nutr 2012;31:652-658.

-57 Taekema DG, Gussekloo J, Maier AB, Westendorp RG, de Craen AJ: Handgrip strength as a predictor of functional, psychological and social health. A prospective population-based study among the oldest old. Age Ageing 2010;39:331-337.

-58 Rolland Y, Lauwers-Cances V, Cristini C, Abellan van Kan G, Janssen I, Morley JE, Vellas B: Difficulties with physical function associated with obesity, sarcopenia, and sarcopenic-obesity in community-dwelling elderly women: the EPIDOS (EPIDemiologie de l'OSteoporose) Study. Am J Clin Nutr 2009;89:1895-1900.

-59 Koster A, Ding J, Stenholm S, Caserotti P, Houston DK, Nicklas BJ, You T, Lee JS, Visser M, Newman AB, Schwartz AV, Cauley JA, Tylavsky FA, Goodpaster BH, Kritchevsky SB, Harris TB; Health ABC study: Does the amount of fat mass predict age-related loss of lean mass, muscle strength, and muscle quality in older adults? J Gerontol A Biol Sci Med Sci 2011;66:888-895.

60 Beavers KM, Hsu FC, Houston DK, Beavers DP, Harris TB, Hue TF, Kim LJ, Koster A, Penninx BW, Simonsick EM, Strotmeyer ES, Kritchevsky SB, Nicklas BJ; Health ABC Study: The role of metabolic syndrome, adiposity, and inflammation in physical performance in the Health ABC Study. J Gerontol A Biol Sci Med Sci 2013;68: 617-623.

-61 Mijnarends DM, Meijers JM, Halfens RJ, ter Borg S, Luiking YC, Verlaan S, Schoberer D, Cruz Jentoft AJ, van Loon LJ, Schols JM: Validity and reliability of tools to measure muscle mass, strength, and physical performance in community-dwelling older people: a systematic review. J Am Med Dir Assoc 2013;14:170-178.

62 Fogelholm M, Malmberg J, Suni J, Santtila M, Kyrolainen H, Mantysaari M: Waist circumference and BMI are independently associated with the variation of cardio-respiratory and neuromuscular fitness in young adult men. Int J Obes 2006;30:962-969.

-63 Zafrir B, Salman N, Amir 0: Joint impact of body mass index and physical capacity on mortality in patients with systolic heart failure. Am J Cardiol 2014;113:1217-1221.

-64 Lemos T, Gallagher D: Current body composition measurement techniques. Curr Opin Endocrinol Diabetes Obes 2017;24:310-314.

-65 Baumgartner RN, Wayne SJ, Waters DL, Janssen I, Gallagher D, Morley JE: Sarcopenic obesity predicts instrumental activities of daily living disability in the elderly. Obes Res 2004;12:1995-2004.

-66 Tyrovolas S, Koyanagi A, Olaya B, Ayuso-Mateos JL, Miret M, Chatterji S, Tobiasz-Adamczyk B, Koskinen S, Leonardi M, Haro JM: Factors associated with skeletal muscle mass, sarcopenia, and sarcopenic obesity in older adults: a multi-continent study. J Cachexia Sarcopenia Muscle 2016;7:312-321.

-67 Honda H, Qureshi AR, Axelsson J, Heimburger O, Suliman ME, Barany P, Stenvinkel P, Lindholm B: Obese sarcopenia in patients with end-stage renal disease is associated with inflammation and increased mortality. Am J Clin Nutr 2007;86:633-638.

-68 Montano-Loza AJ, Angulo P, Meza-Junco J, Prado CM, Sawyer MB, Beaumont C, Esfandiari N, Ma M, Baracos VE: Sarcopenic obesity and myosteatosis are associated with higher mortality in patients with cirrhosis. J Cachexia Sarcopenia Muscle 2016; 7:126-135.

-69 Prado CM, Lieffers JR, McCargar LJ, Reiman T, Sawyer MB, Martin L, Baracos VE: Prevalence and clinical implications of sarcopenic obesity in patients with solid tumours of the respiratory and gastrointestinal tracts: a population-based study. Lancet Oncol 2008;9:629-635.

-70 Kalantar-Zadeh K, Kopple JD, Kilpatrick RD, McAllister CJ, Shinaberger CS, Gjertson DW, Greenland S: Association of morbid obesity and weight change over time with cardiovascular survival in hemodialysis population. Am J Kidney Dis 2005; 46:489-500. 
$>71$ Prado CM, Wells JC, Smith SR, Stephan BC, Siervo M: Sarcopenic obesity: a critical appraisal of the current evidence. Clin Nutr 2012;31:583-601.

-72 Batsis JA, Barre LK, Mackenzie TA, Pratt SI, Lopez-Jimenez F, Bartels SJ: Variation in the prevalence of sarcopenia and sarcopenic obesity in older adults associated with different research definitions: dual-energy X-ray absorptiometry data from the National Health and Nutrition Examination Survey 1999-2004. J Am Geriatr Soc 2013;61:974-980.

-73 Cederholm T, Barazzoni R, Austin P, Ballmer P, Biolo G, Bischoff SC, Compher C, Correia I, Higashiguchi T, Holst M, Jensen GL, Malone A, Muscaritoli M, Nyulasi I, Pirlich M, Rothenberg E, Schindler K, Schneider SM, de van der Schueren MA, Sieber C, Valentini L, Yu JC, Van Gossum A, Singer P: ESPEN guidelines on definitions and terminology of clinical nutrition. Clin Nutr 2017;36:49-64.

$\checkmark 74$ Collins KH, Paul HA, Hart DA, Reimer RA, Smith IC, Rios JL, Seerattan RA, Herzog W: A High-fat high-sucrose diet rapidly alters muscle integrity, inflammation and gut microbiota in male rats. Sci Rep 2016;6:37278.

-75 Yasumoto Y, Hashimoto C, Nakao R, Yamazaki H, Hiroyama H, Nemoto T, Yamamoto S, Sakurai M, Oike H, Wada N, Yoshida-Noro C, Oishi K: Short-term feeding at the wrong time is sufficient to desynchronize peripheral clocks and induce obesity with hyperphagia, physical inactivity and metabolic disorders in mice. Metabolism 2016;65:714-727.

76 Bosy-Westphal A, Müller MJ: Assessment of fat and lean mass by quantitative magnetic resonance: a future technology of body composition research? Curr Opin Clin Nutr Metab Care 2015;18:446-451.

-77 Bosy-Westphal A, Jensen B, Braun W, Pourhassan M, Gallagher D, Müller MJ: Quantification of whole-body and segmental skeletal muscle mass using phase-sensitive 8-electrode medical bioelectrical impedance devices. Eur J Clin Nutr 2017;71:1061-1067.

78 Heymsfield SB, Thomas D, Bosy-Westphal A, Shen W, Peterson CM, Müller MJ: Evolving concepts on adjusting human resting energy expenditure measurements for body size. Obes Rev 2012;13:1001-1014.

-79 Cruz-Jentoft AJ, Landi F, Schneider SM, Zúñiga C, Arai H, Boirie Y, Chen LK, Fielding RA, Martin FC, Michel JP, Sieber C, Stout JR, Studenski SA, Vellas B, Woo J, Zamboni M, Cederholm T: Prevalence of and interventions for sarcopenia in ageing adults: a systematic review. Report of the International Sarcopenia Initiative (EWGSOP and IWGS). Age Ageing 2014;43:748-759.

-80 Weinheimer EM, Sands LP, Campbell WW: A systematic review of the separate and combined effects of energy restriction and exercise on fat-free mass in middle-aged and older adults: implications for sarcopenic obesity. Nutr Rev 2010;68:375-388.

-81 Porter Starr KN, McDonald SR, Bales CW: Obesity and physical frailty in older adults: a scoping review of lifestyle intervention trials. J Am Med Dir Assoc 2014;15:240-250.

-82 Villareal DT, Aguirre L, Gurney AB, Waters DL, Sinacore DR, Colombo E, Armamento-Villareal R, Qualls C: Aerobic or Resistance exercise, or both, in dieting obese older adults. N Engl J Med 2017;376:1943-1955.

-83 Deutz NE, Bauer JM, Barazzoni R, Biolo G, Boirie Y, Bosy-Westphal A, Cederholm T, Cruz-Jentoft A, Krznariç Z, Nair KS, Singer P, Teta D, Tipton K, Calder PC: Protein intake and exercise for optimal muscle function with aging: recommendations from the ESPEN Expert Group. Clin Nutr 2014;33:929-936.

-84 Bauer J, Biolo G, Cederholm T, Cesari M, Cruz-Jentoft AJ, Morley JE, Phillips S, Sieber C, Stehle P, Teta D, Visvanathan R, Volpi E, Boirie Y: Evidence-based recommendations for optimal dietary protein intake in older people: a position paper from the PROT-AGE Study Group. J Am Med Dir Assoc 2013;14:542-559.

-85 McClave SA, Taylor BE, Martindale RG, Warren MM, Johnson DR, Braunschweig C, McCarthy MS, Davanos E, Rice TW, Cresci GA, Gervasio JM, Sacks GS, Roberts PR, Compher C; Society of Critical Care Medicine; American Society for Parenteral and Enteral Nutrition: Guidelines for the provision and assessment of nutrition support therapy in the adult critically ill patient. JPEN J Parenter Enteral Nutr 2016;40:159-211.

-86 Robinson SM, Reginster JY, Rizzoli R, Shaw SC, Kanis JA, Bautmans I, Bischoff-Ferrari H, Bruyère O, Cesari M, Dawson-Hughes B, Fielding RA, Kaufman JM, Landi F, Malafarina V, Rolland Y, van Loon LJ, Vellas B, Visser M, Cooper C; ESCEO working group: Does nutrition play a role in the prevention and management of sarcopenia? Clin Nutr 2018;37:1121-1132.

87 Sharma AM, Kushner RF: A proposed clinical staging system for obesity. Int J Obes 2009;33:289-295.

88 Schollenberger AE, Karschin J, Meile T, Küper MA, Königsrainer A, Bischoff SC: Impact of protein supplementation after bariatric surgery: a randomized controlled double-blind pilot study. Nutrition 2016;32:186-192.

-89 Lee CM, Fan E: ICU-acquired weakness: what is preventing its rehabilitation in critically ill patients? BMC Med 2012;10:115. 